\title{
Postoperative internal iliac artery embolisation as salvage therapy for bleeding in an HIV-positive patient with giant cell tumour of bone
}

\author{
T van den Heever,' BSC, MB ChB; Dipl (Anaes), MMed (Sc Crit Care), Dipl (Transfusion Med); \\ C L Barrett, ${ }^{2}$ MB ChB, Dipl (Transfusion Med); M J Webb, ${ }^{2}$ MB ChB; MMed (Int Med); Cert (Clin Haematology); \\ M G L Spruyt,' MB ChB, MMed (Surg), MMed (Crit Care Med); V J Louw, ${ }^{2}$ MB ChB, MMed (Int Med); Cert (Clin Haematology), PhD (Med Ed) \\ ${ }^{1}$ Department of Critical Care, Faculty of Health Sciences, University of the Free State, Bloemfontein, South Africa \\ ${ }^{2}$ Division of Clinical Haematology, Department of Internal Medicine, Faculty of Health Sciences, University of the Free State, \\ Bloemfontein, South Africa
}

Corresponding author: T van den Heever (theavdheever@gmail.com)

Giant cell tumour of bone (GCTB) is a highly vascular tumour, sporadically complicated by massive bleeding during surgery. We report a rare case of GCTB in an HIV-positive patient who suffered massive blood loss intra- and postoperatively. The patient was a 46-year-old HIV-positive female with symptoms and signs of a pelvic mass, and ultrasound evidence of an ovarian mass. Surgery was performed, and a highly vascular retroperitoneal mass originating from her sacrum was identified. Massive blood loss occurred, which required aggressive resuscitation and transfusion of blood products. Damage control surgery was performed, and bleeding was ultimately only controlled postoperatively using bilateral internal iliac artery radiological embolisation. The patient suffered acute kidney injury, which was multifactorial in aetiology, which recovered within 6 days. She was discharged from ICU in a stable condition 7 days postoperatively.

SAfr J Crit Care 2015;31(1):30-31. DOI:10.7196/SAJCC.177

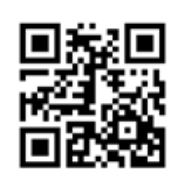

Giant cell tumour of bone (GCTB) is a benign but locally aggressive skeletal neoplasm. It is relatively rare, and mostly affects young adults in the second decade of life. A slight female predominance with a female to male ratio of $3: 2$ is typical of GCTB. It may undergo malignant transformation. ${ }^{[1,2]}$ Only $4 \%$ of patients with GCTB present with the tumour affecting the pelvis. ${ }^{[3]}$

GCTB is known as a highly vascular tumour. ${ }^{[4]}$ Consequently, intraoperative blood loss may be considerable. Preoperative embolisation has been proven successful in reducing intraoperative blood loss. ${ }^{[4]}$ For embolisation to be successful there should be a normal intact clotting system. The aim of embolisation is to devascularise the tumour in order to reduce the amount of blood loss or to serve as a curative procedure, resulting in partial or complete necrosis of the tumour. ${ }^{[2]}$ Usually a 4 or 5 French diagnostic catheter or a microcatheter is used with a gelatine sponge. ${ }^{[2]}$ The gelatine sponge is used only as a temporary measure, as this is part of a staged procedure prior to surgery. Embolisation should be combined with intralesional curettage..$^{[2]}$ Bone cement (polymethyl methacrylate, PMMA) is recommended to fill the area of the bone that is removed. ${ }^{[2]}$

Only two cases of GCTB have ever been reported in HIV-positive patients, and neither of these cases required a massive transfusion of blood products. ${ }^{[1,5]}$

Approval to report this case was obtained from the Ethics Committee of the Faculty of Health Sciences, University of the Free State, the relevant heads of department and the Head of Clinical Services of the Universitas Academic Hospital Complex in Bloemfontein, South Africa.

\section{Case report}

A 46-year-old female patient, who was known to be HIV-positive and treated with combination antiretroviral therapy (CART), was admitted to our intensive care unit (ICU) for postoperative care following a massive blood transfusion in theatre. She had resented to her gynaecologist with a pelvic mass. Abdomino-pelvic ultrasound examination suggested an ovarian mass. Intraoperatively, it was discovered that the patient had a highly vascular, malignantappearing retroperitoneal mass involving the sacrum, and not the ovary as expected. Surgical incision using a Ligasure (Covidian, South Africa) curved small-jaw open sealer/divider was complicated by profuse bleeding after approximately two-thirds of the tumour was resected.

Attempts to surgically control the bleeding failed, and her abdomen was packed with adrenalin-soaked swabs. Coagulation tests were suggestive of either post-transfusional coagulopathy or disseminated intravascular coagulation. No abdominal pressures were measured, but may have been useful to confirm the diagnosis of abdominal compartment syndrome.

The patient received a massive transfusion ( 16 units of red cell concentrate, 15 units of fresh frozen plasma and 2 units of platelets; cryoprecipitate was not available) intraoperatively, and in addition, tranexamic acid, conjugated equine oestrogen (Premarin) and desmopressin were administered. Hypocalcaemia was corrected. Cell salvage could not be used in this patient to reduce allogeneic blood usage owing to the suspected malignancy. Every effort was made to maintain normothermia, normotension and a physiological $\mathrm{pH}$; despite this the patient became hypothermic, hypotensive and acidotic, and the coagulopathy did not resolve. 
As she continued to bleed postoperatively, she received another massive transfusion (7 units of red cell concentrate, $1600 \mathrm{~mL}$ freezedried plasma, 10 units of cryoprecipitate and 1 unit of platelets, as well as $2000 \mathrm{U}$ of prothrombin complex concentrate and $1000 \mathrm{U}$ of factor VIII). Despite all the blood products transfused, the patient did not develop transfusion-associated circulatory overload (TACO) or transfusion-related acute lung injury (TRALI).

As the bleeding continued, the patient was taken to interventional radiology on day 1 postoperatively. A 5 French catheter was inserted, and embolisation of both internal iliac arteries as well as the tumour vessels was performed using an absorbable gelatine compressed sponge (Gelfoam, Pfizer, USA). Bleeding ceased completely and no further blood products were required following embolisation.

The patient subsequently developed acute kidney injury with a peak serum creatinine of $380 \mu \mathrm{mol} / \mathrm{L}$ on day 1 following embolisation. This was attributed to hypotension and contrast nephropathy. The serum creatinine returned to a normal baseline within 6 days. There was no clinical or biochemical evidence of tumour lysis syndrome.

Histology of the resected mass revealed a GCTB arising from the sacrum. The patient was discharged from the ICU in a stable condition 7 days postoperatively.

\section{Discussion}

This case demonstrates the value of bilateral internal iliac artery embolisation when control of massive bleeding from a highly vascular sacral tumour is required. In our case, it was used postoperatively, but it has been advocated as a measure to reduce tumour bulk and to reduce perioperative blood loss if used preoperatively. ${ }^{[6]}$ Preoperative embolisation has been well described in hypervascular bone tumours. ${ }^{[7]}$

Embolisation of the internal iliac arteries may be complicated by ischaemia of the pelvic organs, as well as the spine, buttock and thigh. This may present as gluteal necrosis, paraplegia and impotence, bowel ischaemia, and bladder and perineal necrosis. ${ }^{[8]}$ Postembolisation syndrome, which may include symptoms of pelvic pain and cramping, nausea, vomiting, fever, fatigue, myalgias and malaise with leucocytosis, usually presents within 48 hours and is self-limiting, and typically resolves within 7 days. ${ }^{[9]}$

Damage control surgery comprises three stages, namely: (i) control of bleeding and temporary closure of the abdomen; (ii) aggressive resuscitation while attempting to correct the acidosis, hypothermia and coagulopathy; and (iii) return to the operating theatre for more definitive treatment and closure of the abdominal wall once the patient has been stabilised. ${ }^{[10-12]}$

The patient developed an acute kidney injury, for which she had many risk factors. Her baseline renal function was normal. In spite of the massive blood loss, initial hypovolaemia and hypotension, she had no progressive renal injury, with renal function recovering within 6 days. We believe that this is due to adequate fluid resuscitation that she received in the intra- and postoperative period, as well as avoidance of further exposure to nephrotoxic agents.

\section{Conclusion}

We report a unique coincidental case of an HIV-positive patient with a GCTB complicated by massive intra- and postoperative blood loss and dilutional coagulopathy. Postoperative embolisation of the internal iliac arteries was a life-saving intervention in this patient with uncontrolled blood loss from a highly vascular tumour bed. The patient did not suffer postembolisation syndrome or ischaemic complications from the embolisation. Radiological embolisation should be considered preoperatively in patients with highly vascular bone tumours where massive blood loss is anticipated, but may be considered postoperatively if it was not performed prior to surgery.

Acknowledgements. Dr Daleen Struwig, medical writer, Faculty of Health Sciences, University of the Free State, for technical and editorial preparation of the manuscript.

\section{References}

1. Ares $\mathrm{O}$, Conesa $\mathrm{X}$, Seijas $\mathrm{R}$, Huguet $\mathrm{P}$, González R, Fernández $\mathrm{N}$. [Giant cell tumour of bone in a patient with HIV infection]. Enferm Infecc Microb Clin 2010;28(6):396-397. [http://dx.doi. org/10.1016/j.eimc.2009.09.003]

2. Thomas DM, Desai J. Giant cell tumor of bone. http://www.uptodate.com/patients/content/ topic.do?topicKey= ahzlhQH65OZROGa (accessed 12 February 2012).

3. Turcotte RE. Giant cell tumour of bone. Orthoped Clin North Am 2006;37(1):35-51. [http:// dx.doi.org/10.1016/j.ocl.2005.08.005]

4. Yasko AW. Giant cell tumour of bone. Curr Oncol Rep 2002;4(6):520-526. [http://dx.doi. org/10.1007/s11912-002-0067-2]

5. List AF. Metastatic giant-cell bone tumour in a man positive for HIV. N Engl J Med 1988;318:517

6. Owen RJT. Embolization of musculoskeletal tumours. Radiol Clin North Am 2008;46(3):535543. [http://dx.doi.org/10.1016/j.rcl.2008.02.002]

7. Nair S, Gobin YP, Leng LZ, et al. Preoperative embolization of hypervascular thoracic, lumbar, and sacral spinalcoloumn tumors: Technique and outcomes for a single center. Interv Neuroradiol 2013;19(3):377-385.

8. Andriole GL, Sugarbaker PH. Perineal and bladder necrosis following bilateral internal iliac artery ligation: Report of a case. Dis Colon Rectum 1985;28(3):183-184. [http://dx.doi. org/10.1007/BF02554240]

9. Society of Obstetricians and Gynaecologists of Canada. SOGC clinical practice guidelines. Uterine fibroid embolization (UFE). Number 150, October 2004. Int J Gynaecol Obstet 2005;89(3):305-318.

10. Open Abdomen Advisory Panel, Campbell A, Chang M, et al. Management of the open abdomen: From initial operation to definitve closure. Am Surg 2009;75(11 Suppl):S1-S22.

11. Barker DE, Green JM, Maxwell RA, et al. Experiences with vacuum-pack temporary abdominal wound closure in 258 trauma and general and vascular surgical patients. J Am Coll Surg 2007;204(5):784-792. [http://dx.doi.org/10.1016/j.jamcollsurg.2006.12.039]

12. Aydin C, Aytekin FO, Yenisey C, et al. The effect of different temporary abdominal closure techniques on fascial wound healing and postoperative adhesions in experimental secondary peritonitis. Langenbecks Arch Surg 2008;393(1):67-73. 